\title{
Niche for a technology or technology for a niche?
}

\author{
Sudish C. Murthy, MD, PhD
}

See related article by Marulli et al in the November 2012 issue (J Thorac Cardiovasc Surg. 2012;144:1225-32).

There is little doubt that robotic surgery is here to stay. The real question is if the technology has transitioned from novelty and marketing tool to standard of care. The medical literature is rife with midterm results of robotic procedures as varied as mitral valve repair and thyroidectomy or prostatectomy and pancreatic resection. To add to this accumulating knowledge base, Marulli and colleagues ${ }^{1}$ now submit their multicenter data on robotically assisted resection of thymoma.

Minimally invasive approaches to the mediastinum have been in vogue for well over a decade as technologic advances in imaging and instrumentation have simplified video-assisted thoracic surgery (VATS). Long considered the last bastion of "bright lights and cold steel," the thorax has succumbed to the same driving force that has shaped much of the rest of surgery, namely, the push to perform equally effective operations through smaller, and less morbid, incisions. To this end, anterior mediastinal operations (ie, thymectomy) classically performed through sternal splitting approaches, now often fall under the purview of VATS. Initially, there was considerable pushback from the traditionalists, who feared that equivalent operations could not be performed without sternotomy, whether to palliate myasthenia gravis (MG) or completely resect thymoma. Now those discussions appear somewhat safely positioned in the rearview mirror. Several excellent studies demonstrate largely equivalent efficacy with much less morbidity and support VATS approaches for thymic surgery. ${ }^{2-4}$

Marulli and colleagues ${ }^{1}$ have taken the push for minimal access 1 step farther. Their contribution reviews the outcomes of a 79-patient cohort of robotically assisted thymoma resections. Although some will argue that the reduction in morbidity transitioning from VATS to robotic operations is negligible, intrathoracic instrument articulation and 3-dimensional high-resolution optics clearly permit more elegant and precise operations to be performed robotically. Robotically assisted thymectomy for MG has already been proven safe

\footnotetext{
From the Department of Thoracic and Cardiovascular Surgery, Cleveland Clinic, Cleveland, Ohio.

Disclosures: Author has nothing to disclose with regard to commercial support.

Received for publication Aug 23, 2012; accepted for publication Dec 11, 2012; available ahead of print Jan 14, 2013.

Address for reprints: Sudish Murthy, MD, PhD, Cleveland Clinic/Desk J4-1, 9500

Euclid Ave, Cleveland, OH 44195 (E-mail: murthys1@ccf.org).

J Thorac Cardiovasc Surg 2013;145:737

$0022-5223 / \$ 36.00$

Copyright (c) 2013 by The American Association for Thoracic Surgery

http://dx.doi.org/10.1016/j.jtcvs.2012.12.054
}

and surprisingly efficacious. ${ }^{5}$ The interest in these authors' study revolves around treatment of thymoma, and not MG, and this study is the largest of its kind in this regard.

Thymoma is a curious tumor and still challenges clinicians to develop accurate clinical staging systems. Nonetheless, it is considered eminently curable (particularly for Masaoka stages I-II and World Health Organization histology types $\mathrm{A}, \mathrm{AB}, \mathrm{B} 1$, and $\mathrm{B} 2$ ) with complete resection. Reports of intraoperative tumor capsule rupture and late presentation of incurable disseminated pleural disease had guided therapy toward more conservative, open en bloc operations. VATS surgeons have been responsible for beginning to change this paradigm, but may have to make room for the robotic surgeons, who now report excellent intermediate thymoma cure rates that are easily (at this midterm point) comparable to VATS or open surgical results.

A few lingering issues will still need to be addressed going forward. It is unclear if robotically assisted thymic procedures are less morbid (or more effective) than VATs operations, and given the current climate of cost vigilance, until a definitive benefit can be demonstrated, it might be difficult to disseminate this expensive technology. Importantly, much longer follow-up will be necessary to be certain that robotically assisted resection recapitulates the open experience, both from a thymoma recurrence standpoint and durable palliation of MG (which frequently complicates thymoma presentation). Finally, clear inclusion and exclusion criteria for robotically assisted thymic resections need to be clarified.

My suspicion is that this is just the first of several battlefronts that surgeons using robotic techniques for thoracic procedures will be defending, as looming on the horizon are esophagectomy, antireflux operations, and lobectomy theaters. The familiar combatants will be the open, VATS, and laparoscopic surgeons who come armed with the 1 thing that the robot enthusiasts do not have: Mature data. Let the games begin!

\section{References}

1. Marulli G, Melfi F, Schmid TA, Ismail M, Fanucchi O, Augustin F, et al. Robotaided thoracoscopic thymectomy for early-stage thymoma: a multicenter European study. J Thorac Cardiovasc Surg. 2012;144:1125-30.

2. Takeo S, Tsukamoto S, Kawano D, Katsura M. Outcome of an original videoassisted thoracoscopic extended thymectomy for thymoma. Ann Thorac Surg. 2011;92:2000-5.

3. Pennathur A, Qureshi I, Schuchert MJ, Dhupar R, Ferson PF, Gooding WE, et al Comparison of surgical techniques for early-stage thymoma: feasibility of minimally invasive thymectomy and comparison with open resection. J Thorac Cardiovasc Surg. 2011;141:694-701.

4. Yu L, Zhang XJ, Ma S, Li F, Zhang YF. Thoracoscopic thymectomy for myasthenia gravis with and without thymoma: a single-center experience. Ann Thorac Surg. 2012;93:240-4.

5. Freeman RK, Ascioti AJ, Van Woerkom JM, Vyverberg A, Robison RJ. Long-term follow-up after robotic thymectomy for nonthymomatous myasthenia gravis. Ann Thorac Surg. 2011;92:1018-22. 